\title{
EDITORIAL
}

\section{B Type natriuretic peptide: a good omen in myocardial ischaemia?}

\section{S P D'Souza, G F Baxter}

Heart 2003;89:707-709

\begin{abstract}
Although BNP is now firmly established as a diagnostic and prognostic marker of ventricular dysfunction, its autocrine and paracrine actions within the heart have received less attention
\end{abstract}

7 he natriuretic peptide family consists of a number of structurally homologous but genetically distinct polypeptide mediators. The peptides are highly conserved across mammalian and invertebrate species and, in humans, are released from various tissues in response to physiological and pathological stimuli. All the peptides have at their core a 17-amino acid disulfide ring essential for receptor recognition and biological function.

The first description of secretory granules in the cardiac atria was given in 1956, to be followed by the physiological characterisation of an atrial natriuretic factor in the work of de Bold and colleagues in 1981. ${ }^{1}$ Several further natriuretic peptides have subsequently been identified. These include B type natriuretic peptide (BNP) predominantly from ventricular myocardium (although originally isolated from pig brain $)^{2}$ and $\mathrm{C}$ type natriuretic peptide (CNP) expressed in the nervous system and endothelial cells. ${ }^{3}$ A homologue of the natriuretic factor, DNP, in the venom of the green mamba Dendroaspis angusticeps, is found in plasma and atrial myocardium of normal humans. ${ }^{4}$ Urodilatin is a renal derived natriuretic peptide. ${ }^{5}$ ANP and BNP, the predominant natriuretic peptides in mammalian cardiomyocytes, are stored within secretory granules as pro-peptides, pro-ANP and pro-BNP, that are post-translationally modified by peptide bond cleavage to form the mature circulating peptides and amino (N)-terminal residues. ${ }^{6}$

Biological activity of the peptides generally resides in the mature carboxy-terminal residues, although pro-ANP and pro-BNP may exhibit some activity. The (N)-terminal residues are generally inactive. Relatively little is known about the processing of BNP in the circulation. The peptides are eventually cleared by the natriuretic peptide-C receptor (NPR-C) - a clearance receptor. Binding of natriuretic peptides to NPR-C leads to internalisation and degradation. ${ }^{7}$ Neutral endopeptidase 24.11 (NEP) also takes part in the inactivation of natriuretic peptides and there is a minor contribution from renal excretion. Both NPR-C and NEP are widely expressed in the kidneys, lungs, and the vascular wall.

A variety of physiological and pathological stimuli evoke the release of ANP and BNP. Such stimuli include exercise, hypoxia, ischaemia,

College Street, Londo

gfbaxter@rvc.ac.uk increased wall stress and dilatation of the cardiac chambers, and sepsis. The classical endocrine actions of ANP and BNP, namely vasodilatation and natriuresis, are mediated by interaction with a natriuretic peptide receptor (NPR)-A which is a particulate guanylyl cyclase (pGC). This cyclase subserves the same biochemical function as soluble guanylyl cyclase (sGC) - the principal intracellular receptor for $\mathrm{NO}-$ namely, the conversion of guanosine triphosphate to cyclic guanosine monophosphate (cGMP). NPR-A is widely expressed in cardiovascular tissues, and its activation by ANP and BNP leads to elevation of intracellular CGMP and activation of the CGMP dependent protein kinase (PKG-I). ${ }^{7} \mathrm{CNP}$ engages another receptor subtype, NPR-B, also a pGC receptor, while DNP acts via NPR-A, mediating a predominant vasorelaxing action. ${ }^{8}$

\section{BNP RELEASE IN CARDIAC DYSFUNCTION AND MYOCARDIAL ISCHAEMIA}

BNP is released following left ventricular overloading and wall stress, underpinning its diagnostic and prognostic value in patients with heart failure. ${ }^{9}$ Other cardiac pathologies including hypertensive heart disease, atrial fibrillation, and valvar heart disease are also associated with elevation of circulating BNP. ${ }^{10}$ Experimental and clinical myocardial infarction is clearly associated with gradual and sustained elevation of tissue and circulating BNP. BNP is deemed to be a strong independent predictor of prognosis in patients with heart failure and following myocardial infarction. ${ }^{11}{ }^{12}$ However, the rapid release of BNP following very brief periods of ischaemia, insufficient to provoke irreversible tissue injury or pronounced changes in end diastolic volume, is of considerable interest. Elevated concentrations of BNP in humans are detected following unstable angina $^{13}$ and immediately after short balloon inflations during coronary angioplasty. ${ }^{14}$ In the rat heart, experimental ischaemia of as little as two minutes leads to an immediate increase of BNP outflow, which correlates with the duration of ischaemia. ${ }^{15}$ Such observations are a stimulus to identifying the functional role of BNP in the ischaemic myocardium.

Abbreviations: ANP, atrial natriuretic peptide; BNP, B type or brain natriuretic peptide; CNP, C type natriuretic peptide; DNP, Dendroaspis natriuretic peptide; $K_{\text {ATP }}$ ATP dependent potassium channel; NEP 24.11, neutral endopeptidase; NO, nitric oxide; NPR, natriuretic peptide receptor; pGC, particulate guanylyl cyclase; PKG-I, cGMP-dependent protein kinase subtype l; sGC, soluble guanylyl cyclase 


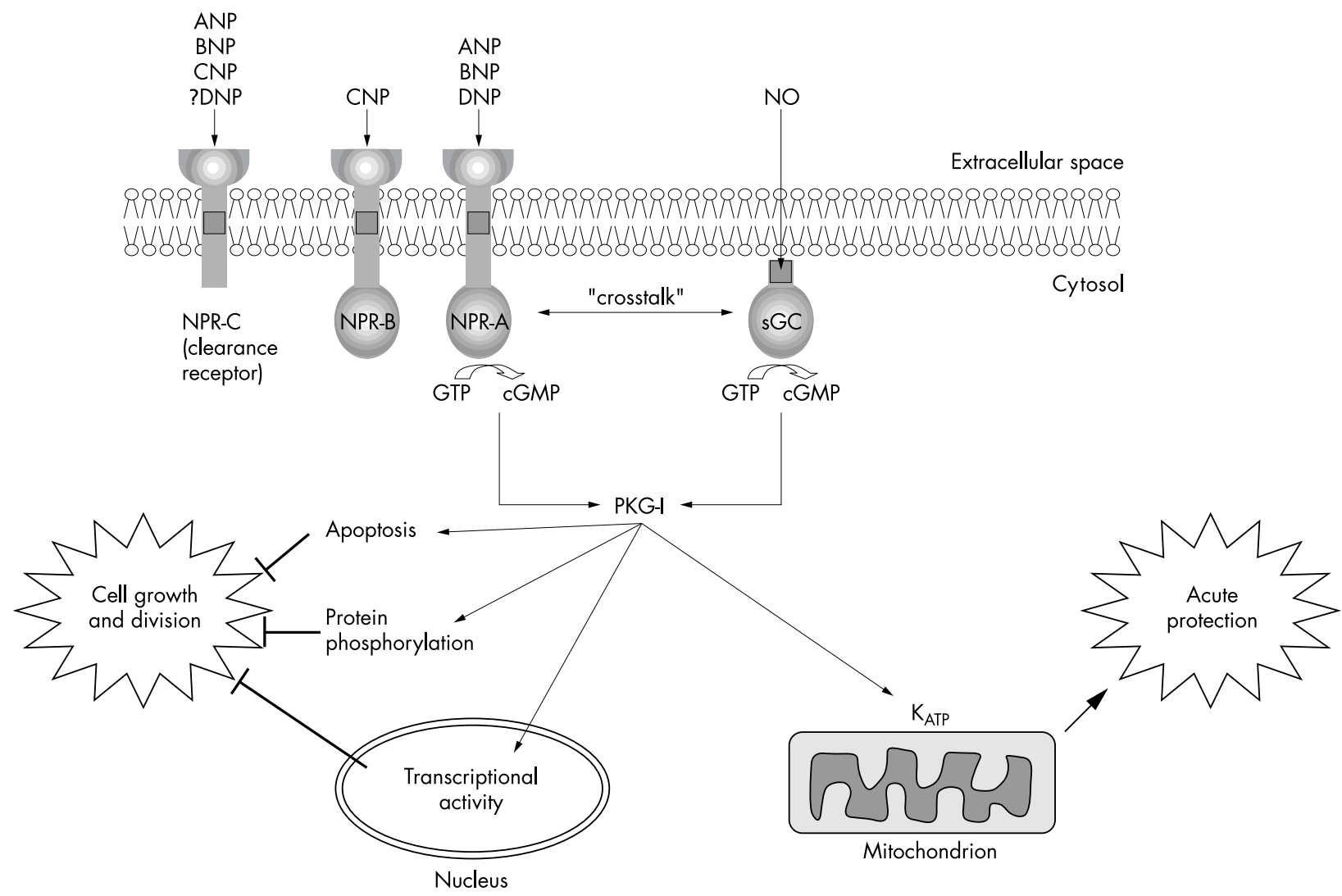

Figure 1 Mechanism of acute protective effect and growth modifying actions of BNP.

\section{BNP MODIFIES ACUTE ISCHAEMIC INJURY}

Myocardial ischaemia triggers the release of a number of endogenous cytoprotective mediators. These include adenosine, opioid peptides, and bradykinin. ${ }^{16}$ However, the role of BNP in modifying acute myocardial ischaemic injury has only recently been identified. In a rat heart model of acute myocardial infarction, exogenously administered BNP limited infarct size in a concentration dependent manner. ${ }^{15}$ This action was independent of the peptide's endocrine actions that lead to systemic haemodynamic unloading, or to recruitment of native coronary collateral vessels, pointing to a primary cytoprotective action. The mechanism of this acute protective effect of BNP appears to be associated with an increase of the second messenger cGMP and involves opening of ATP sensitive potassium $\left(\mathrm{K}_{\text {ATP }}\right)$ channels (fig 1). Pharmacological evidence suggests that this channel may be a mitochondrial $\mathrm{K}_{\mathrm{ATP}}$ channel, rather than the sarcolemmal $\mathrm{K}_{\text {ATP }}$ channel. There is further evidence that the nitric oxide/ soluble guanylyl cyclase $(\mathrm{NO} / \mathrm{sGC})$ system may also play a role in the anti-ischaemic actions of BNP that we have described. ${ }^{17}$ There is recent evidence for a "cross-talk" between the BNP/NPR-A pathway and the NO/sGC pathway in vascular cells and this may also be relevant to the myocardium.

The mitochondrial $\mathrm{K}_{\mathrm{ATP}}$ channel has been prominent recently in relation to protection of the ischaemic myocardium by preconditioning and other protective strategies. Many endogenous protective mediators are thought to produce their anti-ischaemic actions through mitochondrial $\mathrm{K}_{\text {ATP }}$ channel opening, so why should BNP be regarded differently from, say, adenosine or bradykinin? One reason is the novel molecular signalling pathway employed by BNP. We postulate that BNP/NPR-A induced elevation of cGMP with activation of CGMP-dependent protein kinase-I (cGK-I or protein kinaseG-I) is a plausible mechanism of $\mathrm{K}_{\text {ATP }}$ channel opening via the cGMP/cGK-I pathway, and may therefore represent an alternative signalling cascade resulting in tissue protection and salvage.
Most of the endogenous mediators of cardioprotection studied so far act on G-protein-coupled receptors. In several disease states, including cardiac hypertrophy and cardiac failure, there may be downregulation of G-protein-coupled receptor responses. Under these conditions, the BNP/NPR-A signalling pathway could act as a very effective reserve salvage pathway.

\section{BNP MAY INFLUENCE POSTINFARCTION REMODELLING}

The sustained elevation of cardiac BNP expression following myocardial infarction is likely to be a reflection of important counter-regulatory actions of natriuretic peptides on cell growth and proliferation. These actions may include inhibition of fibroblast activity and an antihypertrophic effect on cardiac myocytes.

Following infarction, ANP and BNP exert potent actions on cardiac fibroblasts. Both peptides inhibit collagen synthesis by cardiac fibroblasts in response to hypoxia in vitro and they inhibit fibroblast proliferation in response to angiotensin II stimulation. ${ }^{18}$ Recently, multifocal cardiac fibrosis has been described in mice with deletion of the $b n p$ gene. ${ }^{19} \mathrm{NPR}^{-\mathrm{A}^{-/}}$ knockout mice also develop hypertension with an exaggerated cardiac hypertrophy and fibrosis..$^{20}$ Limited information is available on the role of natriuretic peptides in regulating cardiomyocyte growth. In cultured cardiac myocytes, natriuretic peptides inhibit hypertrophy and in vascular smooth muscle cells, BNP and CNP inhibit growth and proliferation. The mechanism of growth inhibition is far from clear but may involve an inhibitory action on the mitogen activated protein kinase cascade. ${ }^{8}$ Another action of natriuretic peptides that may be relevant to tissue remodelling is the ability to stimulate apoptosis. However, this issue is presently unresolved. Although cyclic nucleotides such as cGMP, the principal second messenger in the BNP/NPR-A signalling pathway, are known to regulate the processes of cell proliferation, differentiation, and apoptosis, there are currently no clear patterns to predict how cGMP could modify apoptosis in ischaemic myocardium. 


\section{CONCLUSION}

In conclusion, BNP is now firmly established as a diagnostic and prognostic marker of ventricular dysfunction, but its autocrine and paracrine actions within the heart have received less attention. Experimental evidence suggests that BNP is a pleiotropic peptide and its salutary effects in acute ischaemia and following infarction go beyond its classical natriuretic and cardiac unloading effects. Therapeutically, this range of actions could be of great benefit. Conceivably, the therapeutic role for recombinant human BNP (nesiritide), currently indicated in the USA for acute decompensated heart failure, ${ }^{21}$ may be extended to limit damage from unstable angina and acute myocardial infarction.

\section{ACKNOWLEDGEMENT}

The authors gratefully acknowledge the support of the National Heart Research Fund and the British Heart Foundation.

\section{Authors' affiliations}

S P D'Souza, The Heart Hospital, London, UK

G F Baxter, The Royal Veterinary College, University of London, London, UK

\section{REFERENCES}

1 De Bold AJ, Borenstein HB, Veress AT, et al. A rapid and potent natriuretic response to intravenous injection of atrial myocardial extract in rats. Life Sci 1981:28:89-94.

2 Sudoh T, Kangawa K, Minamino N, et al. A new natriuretic peptide in porcine brain. Nature 1988;332:78-81

3 Sudoh T, Minamino N, Kangawa K, et al. C-type natriuretic peptide (CNP): a new member of the natriuretic peptide family identified in porcine brain. Biochem Biophys Res Commun 1990;168:863-70.

4 Schirger JA, Heublein DM, Chen HH, et al. Presence of Dendroaspis natriuretic peptide-like immunoreactivity in human plasma and its increase during human heart failure. Mayo Clin Proc 1999;74:126-30.

5 Gagelmann M. Hock D, Forssmann WG. Urodilatin (CDD/ANP-95-126) is not biologically inactivated by a peptidase from dog kidney cortex membranes in contrast to atrial natriuretic peptide/cardiodilatin (alpha-hANP/CDD-99-126). FEBS Lett 1988;233:249-54.

6 Espiner EA, Richards AM, Yandle TG, et al. Natriuretic hormones. Endocrinol Metab Clin North Am 1995;24:481-509.

7 Levin ER, Gardner DG, Samson WK. Natriuretic peptides. N Engl J Med 1998:339:321-8.

8 Silberbach $M$, Roberts CT Jr. Natriuretic peptide signalling: molecular and cellular pathways to growth regulation. Cell Signal 2001;13:221-31.

9 Cowie MR, Mendez GF. BNP and congestive heart failure. Prog Cardiovasc Dis 2002:44:293-321.

10 Nakamura $M$, Endo $H$, Nasu $M$, et al. Value of plasma B type natriuretic peptide measurement for heart disease screening in a Japanese population. Heart 2002;87:131-5.

11 Crilley JG, Farrer $M$. Left ventricular remodelling and brain natriuretic peptide after first myocardial infarction. Heart 2001;86:638-42.

12 Sabatine MS, Morrow DA, de Lemos JA, et al. Multimarker approach to risk stratification in non-ST elevation acute coronary syndromes: simultaneous assessment of troponin I, C-reactive protein, and B-type natriuretic peptide. Circulation 2002;105:1760-3.

13 Talwar S, Squire IB, Downie PF, et al. Plasma $\mathrm{N}$ terminal pro-brain natriuretic peptide and cardiotrophin 1 are raised in unstable angina. Heart 2000;84:421-4

14 Tateishi J, Masutani $M$, Ohyanagi $M$, et al. Transient increase in plasma brain (B-type) natriuretic peptide after percutaneous transluminal coronary angioplasty. Clin Cardiol 2000;23:776-80.

15 D'Souza SP, Yellon DM, Martin C, et al. B-Type natriuretic peptide (BNP) limits infarct size in rat isolated heart via KATP channel opening. Am J Physiol Heart Circ Physiol 2003;284:H1592-600.

16 Baxter GF, Ebrahim Z. Role of bradykinin in preconditioning and protection of the ischaemic myocardium. Br J Pharmacol 2002;135:843-54.

17 D'Souza SP, Yellon DM, Baxter GF. Cardioprotective action of B-type natriuretic peptide is NO-dependent [abstract]. Br J Pharmacol 2003; 138:21P

18 Filippatos GS, Gangopadhyay N, Lalude O, et al. Regulation of apoptosis by vasoactive peptides. Am J Physiol Lung Cell Mol Physiol 2001;281:L749-61.

19 Tamura N, Ogawa Y, Chusho H, et al. Cardiac fibrosis in mice lacking brain natriuretic peptide. Proc Natl Acad Sci USA 2000;97:4239-44.
20 Kuhn M, Holtwick R, Baba HA, et al. Progressive cardiac hypertrophy and dysfunction in atrial natriuretic peptide receptor (GC-A) deficient mice. Heart 2002;87:368-74

21 Keating GM, Goa KL. Nesiritide: a review of its use in acute decompensated heart failure. Drugs 2003;63:47-70.

\section{WEB TOP 10}

\section{www.heartinl.com}

These articles scored the most hits on Heart's website during April 2003

1 Indications for percutaneous and surgical revascularisation: how far does the evidence base guide us?

PM Schofield

May 2003;89:565-70. (Education in Heart)

2 Ambulatory blood pressure monitoring in the management of hypertension

E O'Brien

May 2003;89:571-6. (Education in Heart)

3 Diagnosing cardiac contusion: old wisdom and new insights

KC Sybrandy, MM Cramer, C Burgersdijk

May 2003;89:485-9. (Review)

4 Stress and myocardial infarction

JS Chi, RA Kloner

May 2003;89:475-6. (Editorial)

5 Are we underestimating the full potential of early thrombolytic treatment in patients with acute myocardial infarction?

CJ Terkelsen, JF Lassen, BL Norgaard, JC Gerdes,

TT Nielsen, HR Andersen

May 2003;89:483-4. (Viewpoint)

6 Who would I not give IIb/IIla inhibitors to during percutaneous coronary intervention?

JM McLenachan

May 2003;89:477-8. (Editorial)

7 Injection drug use and right sided endocarditis $R$ Moss, B Munt

May 2003;89:577-81. (Education in Heart)

8 Which heart valve prosthesis for patients aged between 60 and 70 years?

$G$ Hanania

May 2003;89:481-2. (Editorial)

9 What level of physical activity protects against premature cardiovascular death? The Caerphilly study

$S$ Yu, JWG Yarnell, PM Sweetnam, L Murray May 2003;89:502-6. (Cardiovascular medicine)

10 Management of ischaemic mitral regurgitation $B$ lung April 2003;89:459-64. (Education in Heart)

Visit the Heart website for hyperlinks to these articles, by clicking on "Top 10 papers"

www.heartinl.com 